\title{
Tidal variability of the geomagnetic polar cap mesopause above Resolute Bay
}

\author{
Genene M. Fisher, Timothy L. Killeen, Qian Wu, Paul B. Hays \\ Space Physics Research Laboratory, Department of Atmospheric, Oceanic, and Space Sciences, University of \\ Michigan, Ann Arbor
}

\author{
J. M. Reeves \\ Department of Engineering, University of Denver, Colorado
}

\begin{abstract}
Variability in the geomagnetic polar cap neutral wind near the mesopause above Resolute Bay, Canada $\left(74.9^{\circ} \mathrm{N}\right.$, $94.9^{\circ} \mathrm{W}$ ) has been observed by a Fabry-Perot Interferometer, using a circle-to-line detection technique (FPI/CLIO) to observe the $\mathrm{OH}$ Meinel emission. We present an analysis of the first wind measurements obtained with the FPI/CLIO from December 1995 to March 1996. The $\mathrm{OH}(7,3)(892.0 \mathrm{~nm})$ Doppler winds were analyzed for tidal oscillations (defined herein as oscillations with periods which are sub-harmonics of a solar day). Daily spectral analysis, using 50 relatively clear days showed that oscillations between, and including, $12 \mathrm{~h}$ and $8 \mathrm{~h}$ were frequent throughout the winter season in both the meridional and the zonal winds. A non-linear least squares fit, performed on the data from the Jan 22-30 interval, revealed that a $12 \mathrm{~h}$ tidal feature was dominant. Observations of the $\mathrm{OH}$ neutral winds show variations indicating strong tidal wave activity at the mesopause.
\end{abstract}

\section{Introduction}

The dynamics of the middle atmosphere in the geomagnetic polar cap is relatively poorly characterized, due to the lack of ground-based instruments at suitable sites and appropriatelyinstrumented satellites with sufficiently high orbital inclination. Because of this situation, new experimental approaches are being used to determine characteristics of both the small- and largescale waves at northern polar latitudes (Walterscheid et al., 1986; Sivjee et al., 1994; Oznovich et al., 1995; Walterscheid and Sivjee, 1996; Oznovich et al., 1997) and at southern polar latitudes (Collins et al., 1992; Hernandez et al., 1992a; Hernandez et al., 1992b; Hernandez et al., 1993; Sivjee and Walterscheid, 1994; Portnyagin et al., 1998). Results of this work seem to contradict classical theories that suggest that the winter polar region is relatively weakly disturbed by tides - oscillations of integral sub-harmonics of one day (Chapman and Lindzen, 1970; Forbes, 1982a,b). So-called classical tides (Hough modes) are typically expected to have zero amplitude at the geographic poles. In particular, all classical tidal modes, except the zonally symmetric non-migrating tides (zonal wavenumber $s=0$ ), are predicted to vanish at the poles (Forbes, 1982a,b).

Several explanations have been given to justify why various tidal oscillations are being observed at high latitudes. Walterscheid et al., (1981) suggested that pseudotides, generated

\section{Copyright 1999 by the American Geophysical Union.}

Paper number 1999GL900046. 0094-8276/99/1999GL900046\$05.00 from the interaction between gravity wave momentum and thermal tides, may be an efficient mechanism at polar latitudes. Another suggestion is the ducting of mid latitude tidal oscillations to high latitudes (Francis, 1973). Chimonas and Hines (1986) discussed a ducting process that may be effective for waves observed at high altitudes. Interpretations of observations at the northern and southern high latitudes have differed. This is because observations in the southern polar cap have been made at the geographic pole. Research at the south pole have showed that the flow near the geographic pole is characteristic of a zonal wavenumber 1, while scalar variables, such as temperature and emission rates are of zonal wavenumber 0 (Portnyagin et al., 1998; Hernandez et al. 1992a,b,1993). As a result, observed $12 \mathrm{~h}$ waves in the wind measurements are not believed to be from a tidal source (Hernandez et al.,1992a,b,1993; Forbes et al., 1995b; Portnyagin et al.,1998). Temperature measurements in the northern high latitudes have resulted in various interpretations involving reference to inertio-gravity waves, zonally symmetric tides, pseudotides, and non-linear waves (Sivjee et al., 1994; Forbes et al., 1995a; Walterscheid and Sivjee, 1996; Oznvonich et al., 1997).

At present, a clear understanding of the observed tidal oscillations in the polar mesosphere has not been reached and more experimental information is needed to assess the variability in the observed climatology. Our observations at Resolute Bay are unique in a number of ways. First, they represent the first wind observations from the mesopause in the northern polar cap. Second, they are made near the very center of the geomagnetic polar cap, a site where unique magnetospheric coupling might be expected to occur. Third, they provide a continuous and extensive data set for the winter season, which is uncommon for this region. Wind measurements presented in this paper are from our first year data set. We present an analysis of the daily wave variability, particularly focusing on periodicities between $8 \mathrm{~h}$ and $12 \mathrm{~h}$.

\section{The Resolute Data}

Measurements have been made at the Early Polar Cap Observatory, Resolute Bay, Canada (geographic coordinates $74.9^{\circ} \mathrm{N}, 94.9^{\circ} \mathrm{W}$ ) using a Fabry-Perot Interferometer with a circle-to-line optical detection technique (FPI/CLIO). The Circleto-Line Interferometer Optical System (CLIO) is a proprietary technology with the patent held by the University of Michigan. The FPICLIO field of view $\left(2.86^{\circ}\right)$ allows approximately 9 orders of the $\mathrm{OH}(7,3)$ emission to be collected simultaneously by the CCD. Performance of this instrument is described by $\mathrm{Wu}$ et al. (1994), while a detailed description of the CLIO system is given 
by Hays (1990). Continuous data were obtained from December 1995 to March 1996. The $\mathrm{OH}(7,3) \mathrm{P}_{1}(3)$ emission was observed at $892.0 \mathrm{~nm}$, which corresponds to an altitude of about $86 \mathrm{~km}$. The optical measurements are made in the four cardinal directions at an elevation of $45^{\circ}$ above the horizon, and in the zenith. Higher temporal resolution and higher signal to noise ratio are both achieved by CLIO when compared to a conventional FPI. The instrument performs a 90 second integration in each direction, taking less than 10 minutes for a full scan. The FPI of Rees et al., (1990) had comparable temporal resolution. In our data, there were 50 relatively clear days, consisting of less than $40 \%$ cloud cover for more than half of the day.

\section{Results}

Measurements taken from December 1995 to March 1996 at Resolute show wave variability throughout the data set. Figure 1 shows an example of the wind data obtained from the FPI/CLIO. Winds are derived from the $\mathrm{OH}$ spectrum by a non-linear least squares fit. A semidiumal oscillation is apparent for this day. In the plot, the positive direction indicates a flow towards the North or East.

To search for tidal oscillations, a Lomb-Scargle spectral analysis for unevenly sampled data (Press et al., 1992) was performed for each of the 50 relatively clear days. Figure 2 is an example of this spectral analysis for the meridional winds on Jan 25, 1996. An upper limit frequency of $1 \mathrm{~h}^{-1}$ was used. The spectral peaks are above a $99.9 \%$ significance level throughout the whole data set, signifying that they are most probably geophysical. Similar significance level results persist throughout the data set. Figure 2 indicates the presence of a statistically significant peak at $0.083 \mathrm{~h}^{-1}$ frequency ( $12 \mathrm{~h}$ periodicity). The estimation of the uncertainty of the daily frequency, using the half maximum width of the spectral peak, is $\pm 0.03 \mathrm{~s}^{-1}$.

Figure 3 is a color contour plot showing the individual LombScargle analyses for each day plotted in a time series. Strong spectral peaks between $12 \mathrm{~h}\left(0.83 \mathrm{~h}^{-1}\right)$ and $8 \mathrm{~h}\left(0.125 \mathrm{~h}^{-1}\right)$ are
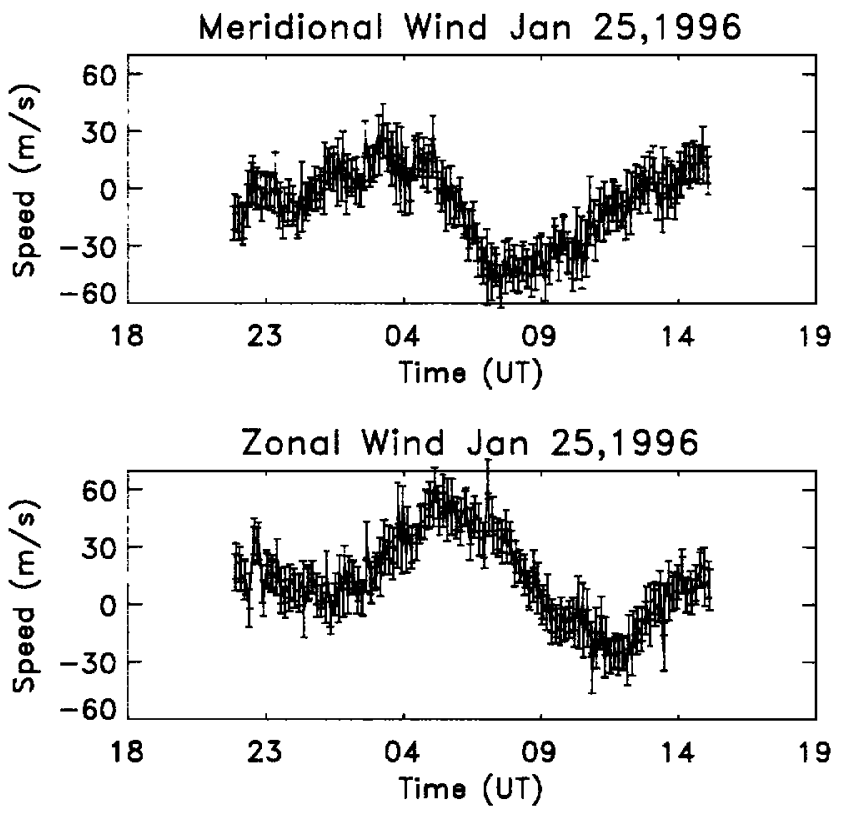

Figure 1. An example of the winds obtained with the FPICLIO at Resolute on Jan 25, 1996.

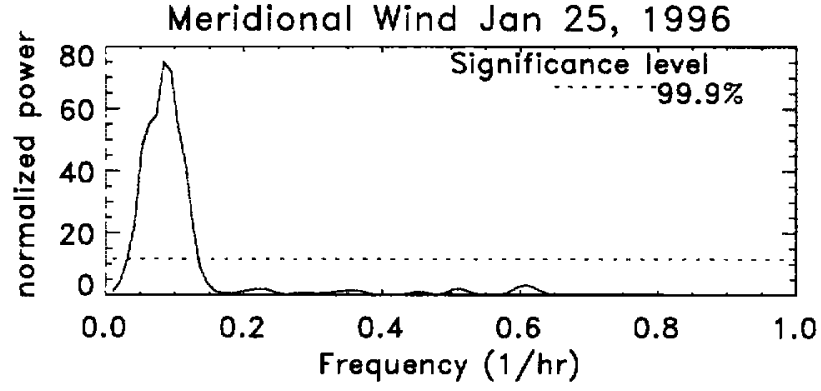

Figure 2. Lomb Scargle spectral analysis for Jan 25, 1996. The meridional wind has a significant spectral peak near $0.083 / \mathrm{hr}$, corresponding to a period of $12 \mathrm{hr}$. The spectral peak has above a $99.9 \%$ probability.

frequently observed in the data. However, the spectral peaks are not "locked in" at specific frequencies, but rather show significant daily variability throughout the $\mathbf{3}$ months. The spectral power is stronger in January than in March, but that may be due to the fewer number of measurements taken as the equinox approaches. The dotted line in Figure 3 shows the limiting frequency, below which the length of the daily data sets is inadequate to determine the relative power unambiguously. This line moves upwards in response to the shortened observing sequences near the equinox. The limiting frequency in December is $0.04 \mathrm{~h}^{-1}(23 \mathrm{~h})$ while it steadily decreases throughout the data until March when it is $0.125 \mathrm{~h}^{-1}(8 \mathrm{~h})$.

After observing the results of the spectral analysis, we chose a sample of data where there was continuous strong spectral power. Wind data from January 22-30 (near new moon) were analyzed using a non-linear least squares fit. Each $12 \mathrm{~h}$ fit is plotted over
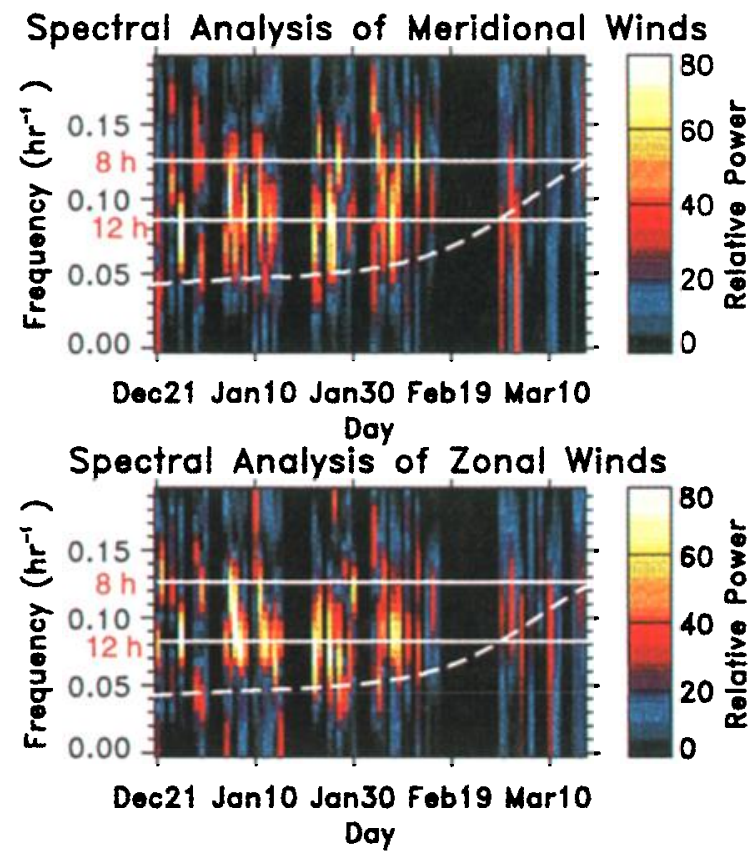

Figure 3. Lomb Scargle spectral analysis is performed for each day using a maximum frequency of $0.2 / \mathrm{hr}$ and then plotted in a time series. Cloudy days were not analyzed, and no data are plotted for those days. Straight white lines are drawn, representing the periodicities at $8 \mathrm{~h}$ and $12 \mathrm{~h}$. The dotted line represents the limiting period due to the decrease in the length of the night. 

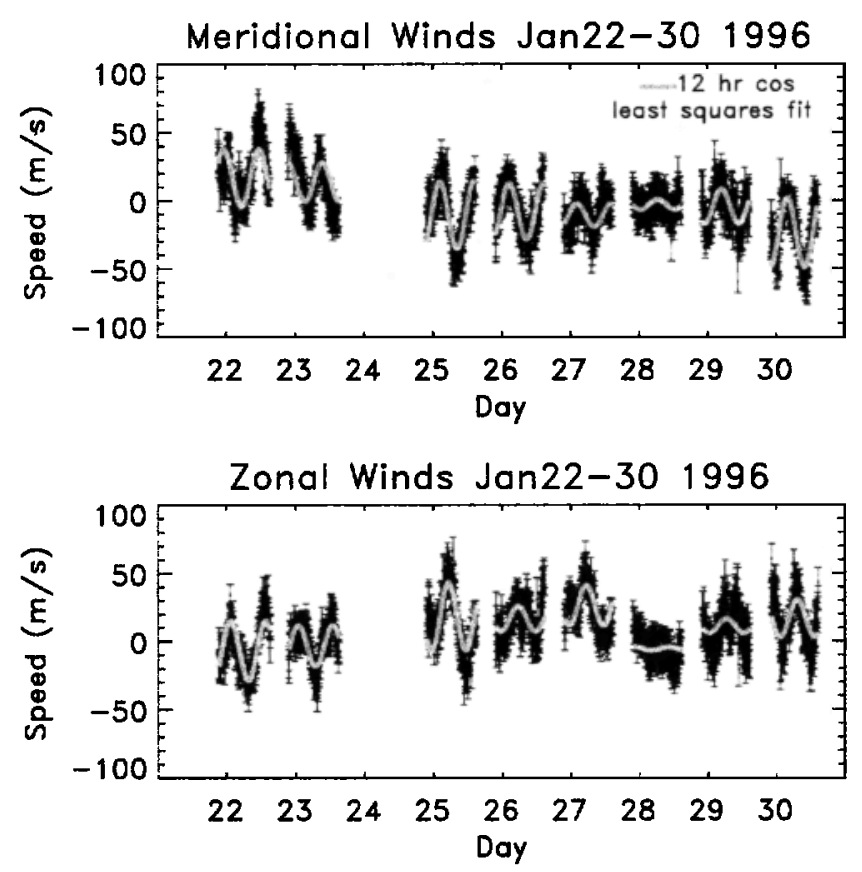

Figure 4. Wind measurements from Resolute during Jan 22-30, 1996. A non-linear least squares fit with a fixed $12 \mathrm{~h}$ period for each day is plotted over the corresponding wind data.

the actual wind data (Figure 4). Values of mean wind, amplitude, and phase shift were obtained from the harmonic terms: $a+b \cos (2$ $\pi / 12+c)$. The data suggests that a semidiumal oscillation in both the meridional and zonal winds persists throughout the week. Figure 5 shows the fitted values for the semidiurnal amplitude, mean wind, and phases.

\section{Discussion and Summary}

The FPICLIO neutral $\mathrm{OH}$ wind measurements at Resolute from December 1995 to March 1996 have been analyzed for dominant daily tidal variability. Our measurements are unique in that they provide mesopause winds from within the northern polar cap. The first analyses from the FPICLIO measurements at Resolute indicates that tidal oscillations are readily detected near the northern geomagnetic polar cap mesopause, with the spectral analysis frequency peak fluctuating between $12 \mathrm{~h}$ and $8 \mathrm{~h}$. Peak frequencies fluctuate from the exact tidal frequencies. The apparent variability in period/frequency may be due to unresolved combinations of tidal frequencies and planetary waves or due to undersampling and aliasing of the geophysical winds. Measurements at very high latitudes displaying $12 \mathrm{~h}$ and $8 \mathrm{~h}$ tides have been reported previously (Myrabo, 1984; Walterscheid et al., 1986; Sivjee et al., 1994; Oznovich et al., 1997). Walterscheid et al. (1996) reported an oscillation varying between $12 \mathrm{~h}$ and $8 \mathrm{~h}$ at Eureka $\left(80^{\circ} \mathrm{N}, 85^{\circ} \mathrm{W}\right)$ and suggested that this may be due to the manifestation of source transience or transfer of energy from one wave to another, or possibly limitation in the spectral resolution. Oznovich et al. (1997) found no single dominant tide in their winds and intensities at Eureka, yet the most persistent tide in the OH airglow layer was terdiumal. They concluded that the terdiurnal tide was consistent with an evanescent zonally symmetric tide, which means that the excitation source is spatially localized rather than global. A significant $8 \mathrm{~h}$ oscillation was also observed at Thule $\left(76.3^{\circ} \mathrm{N}, 68^{\circ} 5 \mathrm{~W}\right)$ in the $\mathrm{OH}$ intensities and temperatures and suggested to be an inertio-gravity wave possibly generated by a non-linear wave interaction (Drob, 1996).

On the days Jan 22-30, a semidiumal oscillation dominates throughout the data (Figure 4). There are some interesting characteristics of the wind components throughout this nine day period. Several cycles of a well-defined wave oscillation with a tidal-like period are sufficient to assume that a tidal feature has been detected. Observing the wind phases, it is obvious that on most days the wind components are very close to quadrature, or a phase difference of 3 hours. A 3 hour phase difference is characteristic of a single tidal mode, which implies that this oscillation has propagated from a different region, since theory does not allow for normal tidal components in the polar cap (Chapman and Lindzen, 1970). However, some days do not exhibit the wind components in quadrature, such as Jan 23,27 , and 28. Other frequency disturbances, consisting of a mixture of modes, may be interacting with this oscillation. The wind phases at Resolute appear to vary from day to day: Forbes (1982b) mentions that relatively slight changes in the phases of individual modes can result in an interference effect that may cause the daily changes in the total tidal variation.

Previously, the $12 \mathrm{~h}$ tide of the polar region in winter has been found to be highly variable in amplitude and phase (Oznovich et al., 1997). Our data also confirms that the amplitudes of the meridional and zonal components of the wind vary. Observing the days from Jan 25-30, the amplitudes seem to drastically decrease until Jan 28 and then increase as Jan 30 is approached (Figure 4).
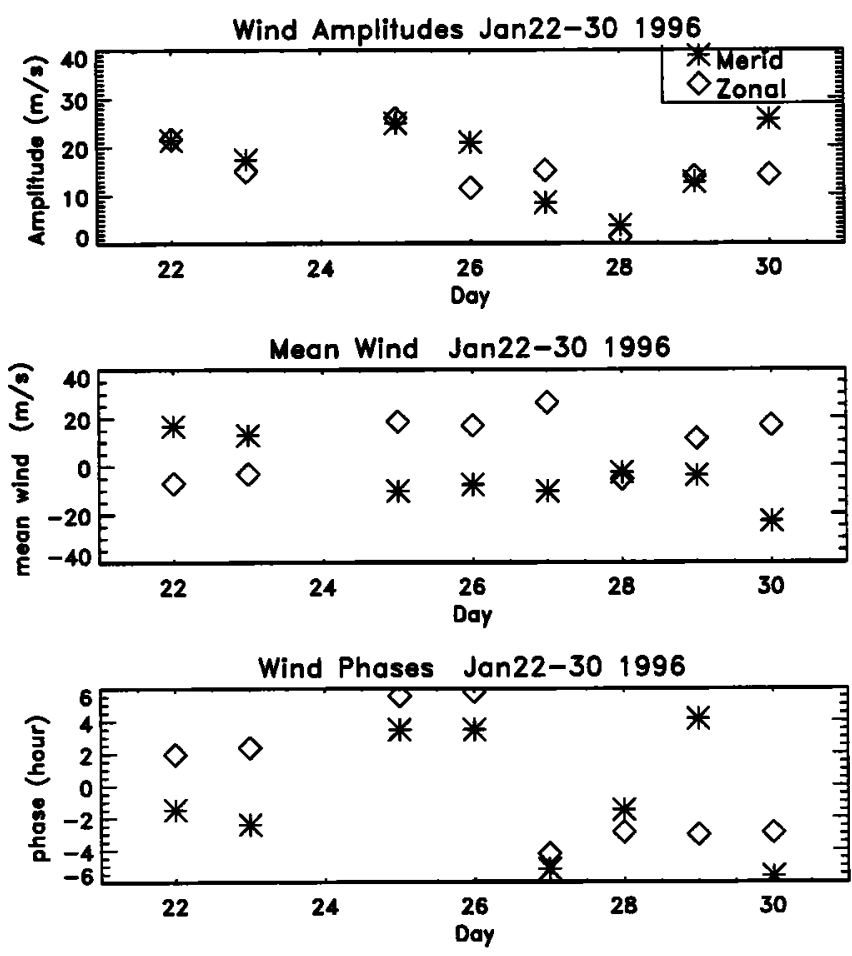

Figure 5. Characteristics of the $\mathrm{OH}$ winds during Jan 22-30, 1996. These values were obtained from a non-linear least squares fit with a fixed $12 \mathrm{~h}$ period. The top panel shows semidiurnal amplitudes, the middle panel displays the mean wind values, and the bottom one shows phases. The phases were calculated to be between $-6 \mathrm{~h}$ and $+6 \mathrm{~h}$. The average uncertainty is $\pm 0.8 \mathrm{~m} / \mathrm{s}$ for the amplitudes, \pm 0.5 for the mean wind values, and \pm 0.2 for the phases. 
There is no obvious explanation for the reason that the amplitudes on Jan 28 are very small. It is possible that the small amplitudes may be due to destructive interference with other wave modes. There is also a variation in the daily mean wind values. During Jan 22-23, the mean wind is in the northwest direction and switches to the southeast direction for Jan 25-30. It is questionable if the source for the shift in the direction of the mean wind is related to the large-scale variation of the wind amplitudes.

According to classical theory, the dominant tidal modes of the solar driven migrating tides which occur at low to mid latitudes tend towards zero at the poles (Chapman and Lindzen, 1970). Therefore, it is likely that the wave oscillations near tidal frequencies in the polar cap regions are dominated by inertiogravity waves, zonally symmetric non-migrating tidal modes, pseudotides, and non-linear waves (Oznovich et al.,1997; Walterscheid and Schubert, 1995; Forbes et al., 1995a). However, a zonally migrating tidal structure has been shown to be significant in calculations using the Global Scale Wave Model (GSWM) (Hagan et al., 1996) and has also been identified in the diurnal tide (Fraser et al.,1995).

Our results at Resolute show that quasi-periodic oscillations near tidal frequencies occur frequently at the mesopause. A Lomb-Scargle spectral analysis uncovers frequencies between 12 $\mathrm{h}$ and $\mathbf{8} \mathrm{h}$ from December to March. This persistence of the tidal harmonics suggests that the oscillations observed are most likely tidal features. Therefore, it appears that there must be a persistent source for these tidal-like oscillations at the polar latitudes.

Acknowledgments. This research was supported by NSF grant ATM96-12839

\section{References}

Chapman, S., and R. S., Lindzen, Atmospheric Tides, 200 pp., Gordon and Breach, New York, 1970.

Chimonas, G. and C.O., Hines, Doppler ducting of atmospheric gravity waves, J. Geophys. Res., 91, 1219-1230, 1986.

Collins, R. L., D.C Senft, and C.S Gardner, Observations of a $12 \mathrm{~h}$ wave in the mesopause region at the South Pole, Geophys. Res. Lett., 1957$1960,1992$.

Drob, D. P.. Ground-based optical detection of atmospheric waves in the upper mesosphere and lower thermosphere, Ph.D. thesis, Univ. of Michigan, Ann Arbor, 1996.

Forbes, J. M., Atmospheric Tides 1. Model description and results for the solar diurnal component, J. Geophys. Res., 87, 5222-5240, 1982a.

Forbes, J. M., Atmospheric Tides 2. The solar and lunar semidiurnal components, J. Geophys. Res., 87, 5241-5252, $1982 \mathrm{~b}$.

Forbes, J. M., Tidal and planetary waves, The upper mesosphere and thermosphere: a review of experiment and theory, edited by $\mathrm{R}$. $\mathrm{M}$. Johnson and T. L. Killeen, Geophysical Monograph Series, vol 87, AGU, 1995a.

Forbes, J. M, N.A. Makarov, Y.I. Portnyagin, First results from the meteor radar at South Pole: a large 12-hour oscillation with zonal wavenumber one, Geophys. Res. Lett., 22,3247-3250, 1995 b.

Francis, S. H., Lower atmospheric gravity modes and their relation to middle-scale traveling ionospheric disturbances, J.Geophys. Res., 78,8289-78,8295, 1973.
Fraser, G.J., Yu. L. Portnyagin, J. M Forbes, R. A. Vincent, I. A. Lysenko, N. A. Makarov, Diumal tide in the Antarctic and Arctic mesosphere/lower thermosphere regions, J. Atoms. Terr. Phys., 57, 383-393, 1995.

Hagan, M.E., Comparative effects of migrating solar sources on tidal signatures in the middle and upper atmosphere, J. Geophys. Res.,101, 21,213-21,222, 1996.

Hays, P.B., Circle to line interferometer optical system, Appl. Opt., 29, 1482-1489, 1990.

Hernandez, G, R.W. Smith, and J .F. Conner, Neutral wind and temperature in the upper mesopause above South Pole, Antarctica, Geophys, Res. Lett., 19.53-56, 1992a.

Hernandez, G., R.W. Smith, G.J. Fraser, and W. L. Jones, Large-scale waves in the upper mesosphere at Antarctic high latitudes, Geophys, Res.Lett., 19, 1347-1350, 1992b.

Hernandez, G., G. J., Fraser, and W.L. Jones, Mesospheric 12 hour oscillation near South Pole, Antarctica, Geophys. Res. Lett., 20, 1787 1790, 1993.

Myrabo, H.K., Temperature variation at mesopause levels during winter solstice at 78 N, Planet. Space Sci., 37, 249-255, 1984.

Oznovich, I., D.J. McEwen, and G.G. Sivjee, Temperature and airglow brightness oscillations in the polar mesosphere and lower thermosphere, Plant. Space Sci., 43, 1121-1130, 1995.

Oznovich. I, D. J. McEwen, G. G. Sivjee, and R. L. Walterscheid, Tidal oscillations of the Arctic upper mesosphere and lower thermosphere in winter, J. Geophys. Res., 102, 4511-4520, 1997.

Press, W. H., S.A. Teukolsky, W. T. Vetterling, B. P. Flannery, Numerical Recipes, Cambridge University Press, 1992.

Rees, D., A. Aruliah, T. J. Fuller-Rowell, V. B. Wickwar, R. J. Sica, Winds in the upper mesosphere at mid-latitude: first results using an imaging Fabry-Perot interferometer, Geophys. Res. Lett., 17, 1259$1262,1990$.

Sivjee, G.G., and R.M. Hamwey, Temperature and chemistry of the polar mesopause OH, J.Geophys. Res ,92, 4663, 1987.

Sivjee, G.G., and R. L. Walterscheid, Six-hour zonally symmetric tidal oscillations of the winter mesosphere over the south pole station, Planet Space Sci., 42, 447-453, 1994.

Walterscheid, R.L., Inertio-gravity wave induced accelerations of mean flow having an imposed periodic component: implications for tidal oscillations in the meteor region, J. Geophys. Res., 86, 9698, 1981.

Walterscheid, R. L., G.G. Sivjee, G. Schubert and R.M. Hamwey, Large amplitude semi-diurnal variations in the polar mesopause: evidence of a pseudotide, Nature, 324, 347, 1986.

Walterscheid, R. L., and G. Schubert, A dynamical chemical model of fluctuations in the $\mathrm{OH}$ air-glow driven by migrating tides, stationary tides and planetary waves, J. Geophys. Res., 100, 17, 433-17, 450, 1995.

Walterscheid, R. L., G.G. Sivjee, Very high frequency tides observed in the airglow over Eureka, Geophys. Res. Lett., 23, 3651-3654, 1996.

Wu, J., J. Wang, and P.B. Hays, Performance of a circle-to-line optical system for a Fabry-Perot interferometer; a laboratory study, Applied Optics, 33, 7823-7828, 1994.

G. M. Fisher, T. L. Killeen, Q. Wu, P. B. Hays, Space Physics Research Laboratory,University of Michigan, 2455 Hayward St., Ann Arbor, MI 48109. (email: fisherg@umich.edu; tkilleen@umich.edu; qwu@umich.edu; phays@umich.edu)

J. M. Reeves, Department of Engineering, University of Denver, Denver, CO, 80208. (email: jreeves@du.edu)

(Received August 4, 1998; revised December 21, 1998; accepted January 6, 1999.) 